\title{
Willingness and attitude of the Arab world population towards solid organ
}

\author{
Ahmed Alanzi
}

Salmaniya Medical Complex, Manama, Bahrain

Background: Organ transplantation is the most important treatment option for final stage organ disease and organ failures. Some studies found out that willingness of organ donation is multi-factorial. Religious and cultures factors are playing big role in influencing the decision of donation. There are also other factors like family influences, trust of health care system and the individual's knowledge and awareness of the organ donation process. This study aims to determine the willingness of organ donation among Arab regions.

Methods: Based on a review of the literature on organ donation, a cross sectional study was designed and online questionnaire with two forms of Arabic and English were distributed to citizens of Arab countries. Data entered in SPSS ver. 23.

Results: Our research illustrated that only $17 \%$ showed their willingness to donate in future and the most acceptable organs to be donated after death were kidneys (57.8\%), followed by liver (45.1\%). Those who experienced organ transplantation showed more tendency for organ donation compared to those who had not $(P<0.0001)$. Additionally, being involved in charity works in the past was associated with the participants' willingness for organ donation as well. Past-transplantation experience donors tend more to accept paid organ donation with a $P<0.0001$. Nevertheless, neither monthly income $(P=0.303)$ nor being participated in charity works in the past $(P=0.053)$ are related to the acceptability of getting paid for organ donation.

Conclusions: The present research revealed the extent of willingness of the general population in the Arab world to donate solid organs generally and in special circumstances e.g., deceased donation, live donation and donation to relatives and non-relatives. It is clear that the need of solid organ donation overweighs the population acceptance, except in some special events where the acceptance was obviously higher.

Corresponding author: Ahmed Alanzi

E-mail: ahmedo-1995@hotmail.com

(C) The Korean Society for Transplantation

This is an Open Access article distributed under the terms of the Creative Commons Attribution Non-Commercial License (http://creativecommons.org/licenses/by-nc/4.0/) which permits unrestricted non-commercial use, distribution, and reproduction in any medium, provided the original work is properly cited 